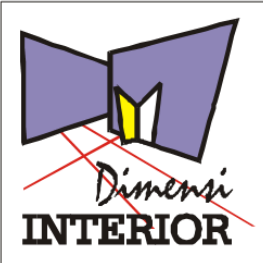

http://dimensiinterior.petra.ac.id

\title{
Akulturasi Budaya Pada Interior Gereja Katolik (Studi Kasus: Gereja Gemma Galgani Ketapang, Kalimantan Barat)
}

\author{
Karin Oscarina | Lintu Tulistyantoro | Grace Setiati Kattu \\ Program Studi Desain Interior, Universitas Kristen Petra, Surabaya \\ Email: m41414076@john.petra.ac.id
}

\begin{abstract}
ABSTRAK
Gereja Gemma Galgani Ketapang adalah gereja katolik yang sangat unik. Gereja ini mencerminkan sebuah akulturasi budaya lokal yang tampak pada ornamen dan elemen yang diaplikasikan pada interiornya. Budaya lokal yang diterapkan pada elemen dan ornamen adalah budaya Dayak. Ornamen Dayak tidak hanya sekedar memenuhi estetika, elemen tersebut tentunya memiliki makna yang dalam sesuai dengan konteks masyarakatnya. Permasalahan muncul apakah elemen dekoratif tersebut sejalan dengan kepercayaan agama Katolik? Metode yang digunakan dalam penelitian ini adalah kualitatif deskriptif dengan pendekatan komparasi. Data dicapai dengan cara melakukan observasi, dokumentasi dan wawancara dengan pakar. Analisa dilakukan dengan cara membandingkan antara data lapangan, literatur dan pendapat pakar melalui pentabelan. Percampuran budaya Dayak dengan Katolik terlihat baik fisik maupun non fisik, seperti pada pola organisasi ruang yang sama dengan struktur Batang Garing yang merupakan kepercayaan agama Kaharingan. Penggunaan warna dan ornamen elemen pembentuk ruang dan perabot terdapat motif Dayak yang memiliki persamaan makna dengan kepercayaan Katolik. Kesamaan tidak hanya pada visualisasi tetapi lebih menekankan kepada makna dari ornamen tersebut.
\end{abstract}

Kata Kunci: interior, gereja, Katolik, akulturasi, Dayak.

\section{ABSTRACT}

Gemma Galgani Ketapang Church is a very unique Catholic church. This church reflects an acculturation of local culture that appears in ornaments and elements that are applied to the interior space, particularly the Dayak culture. Dayak ornaments not only fulfill aesthetics, these elements certainly have deep meaninsg in accordance with the context of the community. The research problem is whether these decorative elements are in line with Catholic beliefs. The method used in this study is descriptive qualitative with a comparative approach. The data are obtained by conducting observations, documentation and interviews with experts. The analysis was done by comparing between field data, literature and experts' opinions through labeling. The mixing of Dayak and Catholic culture can be seen both physically and non-physically, as in the organizational pattern of the same space as the Batang Garing structure which is a form of Kaharingan religious belief. The use of colors and ornaments on spatial elements and furniture have Dayak motifs that have similar meanings to Catholic beliefs. This similarity is not only in emphasized through visualization but also in the meaning of the ornaments.

Keywords: interior, church, Catholic, aculturation, Dayak.

\section{PENDAHULUAN}

Katolik adalah agama yang berasal dari benua Eropa. Masuknya agama Katolik ke wilayah di Indonesia menyebabkan satu proses sosialisasi yaitu akulturasi. Hal ini nampak pada banyak aspek yang meliputi, prosesi, seni dan budaya serta arsitektur. Secara umum definisi akulturasi merupakan perubahan budaya ditandai dengan adanya hubungan antara dua kebudayaan, keduanya saling memberi dan menerima. Seperti yang dikemukakan oleh Herskovitz, akulturasi adalah fenomena yang terjadi ketika kelompok-kelompok yang memiliki budaya berbeda terlibat kontak yang berlangsung secara langsung, dengan perubahan terus menerus, sejalan dengan pola-pola budaya dari masing-masing kelompok.
Tujuan dari akulturasi adalah penggabungan dua budaya untuk saling bertukar dan mengenal satu sama lain sehingga perbedaan itu lebih mudah diterima oleh kebudayaan masing-masing.

Seiring perkembangan zaman terjadi proses akulturasi antara budaya Indonesia dengan budaya luar. Proses tersebut dapat kita lihat di salah satu wilayah di Indonesia yaitu di pulau Kalimantan. Kalimantan merupakan wilayah yang memiliki budaya yang kuat dan kental. Suku Dayak merupakan salah satu suku terkenal yang mendiami wilayah Kalimantan termasuk di Kalimantan Barat termasuk salah satunya adalah di kota Ketapang. Masuknya agama Katolik dalam wilayah masyarakat Dayak menyebabkan terjadinya akulturasi, 
salah satu alasannya adalah adaptasi agama Katolik terhadap konteks masyarakat suku Dayak.

Gereja Gemma Galgani merupakan gereja Katedral di wilayah Ketapang yang diberkati pada tanggal 10 Juni 1962. Visi misi gereja ini cukup unik yaitu menggunakan unsur lokal yang mengacu pada budaya Dayak. Misi keuskupan Ketapang adalah sebagai gereja lokal yang berusaha semakin mandiri dan terus menerus berjuang mewujudkan Kerajaan Allah Lebih detail lagi yaitu mengakar dalam keluarga dan budaya setempat dengan menciptakan dan mendayagunakan tata kerja yang mendukung. Gereja ini didesain oleh salah satu Romo yang bertugas yaitu Romo Matheus Juli dimana beliau merupakan orang Dayak asli dan ingin mengangkat budaya Dayak. Saat diwawancarai Romo Matheus Juli menjelaskan bahwa gereja ini merupakan rumah Tuhan, setiap orang yang masuk harus merasakan Tuhan hadir. Tuhan orang dayak adalah bukan Tuhan orang asing, bukan Tuhannya orang Eropa, bukan Tuhannya dari Sumatra atau dari Jawa tetapi Tuhannya orang Ketapang, itu yang mau saya wujudkan. Maka dari itu beliau merenovasi interior gereja dalam konteks sentuhan budaya lokal masyarakat Dayak.

Gereja Gemma Galgani dipilih menjadi objek penelitian karena gereja ini mengangkat budaya lokal setempat yang diaplikasikan pada interior gereja, sehingga seperti yang dikatakan oleh Romo Matheus Juli orang yang datang merasakan Tuhannya orang Ketapang. Budaya lokal Dayak dapat dilihat dari ornamen-ornamen serta ukiran yang ada pada interior gereja, beberapa material yang digunakan menggunakan material lokal. Gereja ini didesain langsung oleh salah satu imam yang asli orang Dayak yaitu Rm. Matheus Juli beliau mengerti antara budaya Dayak dan budaya Katolik. Penggabungan dua budaya yang diaplikasikan pada interior gereja membuat gereja ini menarik untuk diteliti. Metode Penelitian yang digunakan adalah deskriptif kualitatif. Pengambilan data ada metode ini adalah dengan melakukan observasi langsung, tinjauan pustaka dan wawancara. Sedangkan analisis data menggunakan komparasi antara tinjauan pustaka dengan data lapangan.

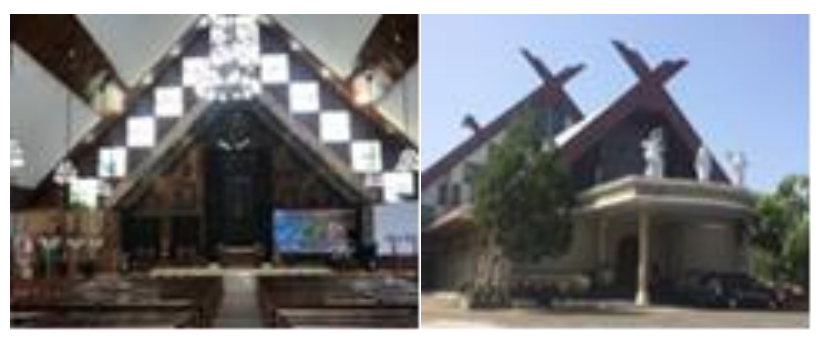

Gambar 1. Interior dan tampak depan Gereja.

\section{TINJAUAN PUSTAKA}

Akulturasi akan terjadi apabila terdapat dua kebudayaan atau lebih yang berbeda sama sekali (asing dan asli) berpadu sehingga proses-proses ataupun peleburan unsur- unsur kebudayaan asing secara lambat laun diolah sedemikian rua ke dalam kebudayaan asli dengan tidak menghilangkan identitas maupun keasliannya. Menurut Prof. Dr. Koentjaraningrat [1] akulturasi merupakan proses sosial yang timbul dari kelompok manusia tertentu yang dihadapkan dengan suatu kebudayaan tertentu dihadapkan dengan unsurunsur dari suatu kebudayaan asing dengan sedemikian rupa, sehingga lambat laun kebudayaan asing itu diterima oleh sekelompok orang tanpa menghilangkan kebudayaan kelompok itu sendiri. Akulturasi merupakan perubahan budaya ditandai dengan adanya hubungan antara dua kebudayaan, keduanya saling memberi dan menerima atau shoter. Sumandiyo Hadi juga mengatakan bahwa akulturasi adalah the encounter between two cultures (pertemuan antara dua kebudayaan). Akulturasi dapat digambarkan sebagai pola penyatuan antara dua kebudayaan, penyatuan antara dua kebudayaan, penyatuan disini tidak berarti bahwa kesamaannya lebih banyak dari pada perbedaannya, namun berarti kedua kebudayaan yang saling berinteraksi menjadi semakin serupa dibanding sebelum terjadinya kontak antar keduanya. Kesimpulan pengertian akulturasi merupakan pertemuan atau percampuran dua kebudayaan yang tidak menghilangkan nilai budaya itu sendiri dan saling menerima kebudayaan tersebut.

Kata Gereja berasal dari bahasa Portugis yaitu igreja, yang berasal dari kata Yunani: eklesia yang berarti mereka yang dipanggil, kaum, golongan; dan Kyriake yang berarti yang dimiliki Tuhan [2]. Simbol warna-warna yang digunakan pada gereja Katolik terdiri dari beberapa warna seperti:

- Kuning: mengungkapkan kemuliaan, kemenangan, dan kegembiraan, biasanya bisa dipertemukan dengan warna putih dan digunakan pada hari natal, paskah dll.

- Merah: lambang dari roh kudus, darah, api, cinta kasih, pengorbanan, dan kekuatan. Warna ini dipakai pada hari raya Jumat Agung, Minggu Palma, Pentakosta, dan pesta para martir.

- Putih: mengungkapkan kegembiraan dan kesuciaan, biasanya bisa dipertemukan dengan warna kuning dan digunakan pada hari natal, paskah, dan kamis putih.

- Ungu: mengungkapkan tobat, duka, dan matiraga, dipakai pada masa advent, paskah, dan misa pemakaman.

- Hijau: melambangkan harapan, syukur, dan kesuburan, dan dipakai pada hari hari dalam misa biasa.

- Hitam: hitam mengungkapkan kesedihan atau berkabung, dipakai saat misa arwah atau pemakaman. Biasanya dapat diganti dengan warna ungu [3].

Banyak simbol-simbol yang terdapat dalam gereja Katolik, seperti:

- Alfa Omega. Simbol huruf pertama dan terakhir dalam abjad Yunani. Makna dari tanda ini adalah:

- Allah sebagai awal dan akhir, Allah merupakan asal dan pencipta dari semua yang ada dan kepada Allah juga semuanya akan kembali

- Sifat Ilahi Yesus sebagai Tuhan atas segala sesuatu yang ada, semua alam semesta dan segala zaman.

- Anak Domba Allah. Yang dimaksud dengan Anak Domba Allah adalah Yesus.

- Chi dan Rho. Simbol Chi dan Rho merupakan tulisan yang berasal dari Yunani yang terdiri dari dua huruf, chi (X) dan rho (P) untuk melambangkan Kristus. 
- Pokok Anggur. Simbol ini berupa gambar batang anggur dan buah-buahannya dan sering terlibat pada ukiran kayu dan lukisan. pokok anggur melambangkan Yesus.

- Lingkaran dan Segitiga. Segitiga melambangkan Allah Tritunggal. Lingkaran merupakan lambang kekekalan, tidak ada awal dan tidak ada akhir. Lambang ini memiliki makna kekekalan dari Allah Tritunggal.

- INRI. Huruf inisial latin yang tertulis di atas salib: Ieus Nazarenus Rex Iudeaorum (Yesus orang Nazaret, raja orang Yahudi). Diletakan di atas salib.

Dayak adalah nama kolektif untuk berbagai suku asli di Kalimantan. Secara umum dapat dikatakan masyarakatmasyarakat yang tergolong kedalam kelompok suku Dayak menghuni pedalaman di wilayah Kalimantan. Suku Dayak memiliki kepercayaan yang sudah ada sejak jaman nenek moyang, agama ini percaya akan penguasa alam semesta atau Tuhan biasa disebut Ranying Hatalla. Kaharingan berasal dari kata Haring yang berarti hidup. Tempat ibadah agama Kaharingan adalah Balai Basarah Agama Kaharingan percaya dengan ornamen Batang Garing Belum, Batang berarti pohon sedangkan Belum berarti hidup. Batang Garing Belum merupakan pohon kehidupan yang selalu meneteskan air suci bagi hidup manusia di bumi, menggambarkan tentang Tuhan menjadi sumber segala hidup manusia, maka Batang Garing Belum sering disebut pohon kehidupan. Bentukan yang terdapat pada ornamen ini adalah bentuk organis terutama bentuk organis tumbuhan tetapi hanya lukisan kiasan religius suku Dayak.

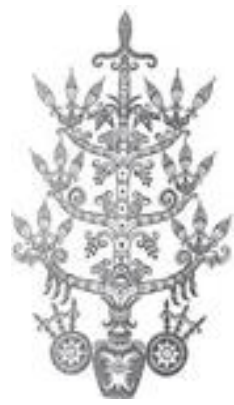

Gambar 2. Batang Garing [4]

Nama tempat tinggal pada daerah masyarakat Kalimantan Barat adalah rumah Panjang. Rumah Panjang berbentuk persegi panjang, karena dihuni oleh beberapa keluarga sehingga terdapat puluhan pintu maka bentuk bangunan persegi panjang yang memanjang ke kanan dan kiri. Jenis ruang dibagi menjadi 4 bagian yaitu teras (pante), Serambi (sami), ruang inti (bilik) dan dapur.

\section{GEREJA KATOLIK KETAPANG}

Gereja ini merupakan gereja Katedral yang berada di wilayah Ketapang Kalimantan Barat, terletak di Jl. A. Yani no 72 Ketapang dan diberkati pada 10 Juni 1962. Gereja Gemma Galgani merupakan gereja yang memiliki konsep mengakar pada nilai-nilai budaya Dayak, Romo Matheus Juli menginginkan setiap orang yang masuk merasakan Tuhan hadir, Tuhan yang hadir merupakan Tuhan asli orang sini (Ketapang) bukan Tuhan orang asing, bukan Tuhannya orang Eropa, bukan Tuhannya dari Sumatra atau dari Jawa tetapi Tuhannya orang Ketapang.

Gereja ini memadukan budaya Dayak dengan kepercayaan Katolik. Fokus pada penelitian ini adalah akulturasi pada interior gereja terutama ornamen-ornamen serta makna yangterkandung yang diaplikasikan pada elemen pembentuk ruang dan elemen pengisi ruang pada bangunan gereja. Struktur organisasi ruangnya terbagi atas area fasad, panti umat, panti imam dan area tabernakel.

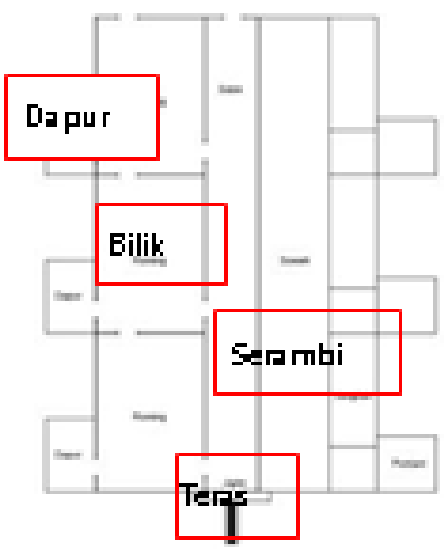

Gambar 3. Denah rumah Panjang Sumber: Arsitektur Tradisional Daerah Kalimantan Barat
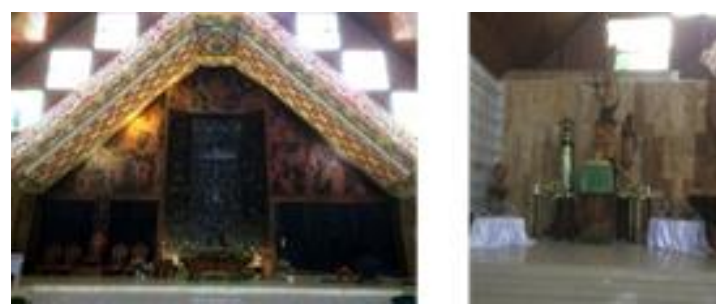

Gambar 4. Interior Objek Penelitian.

\section{AKULTURASI BUDAYA DAYAK DAN KATOLIK}

Terdapat persamaan antara struktur ruang pada gereja dengan struktur Batang Garing dimana pada bagian luar sama dengan Runjan dimana duniawi terjadi sedangkan bagian tengah atau panti umat merupakan ornamen pada bagian tengah, Batang Garing merupakan pohon kehidupan yang selalu meneteskan air suci bagi hidup manusia di bumi, sama seperti umat yang memasuki memasuki panti umat terdapat bejana air suci dimana air suci ini mempersiapkan umat dari hal duniawi menuju Panti Umat. Sedangkan Bunu sama seperti area Panti Imam yang sakral atau sempurna sehingga ukiran yang terdapat pada area tersebut seperti Allah Bapa, Bunda Maria, Yesus dan para penginjil. Seperti yang terlihat pada potongan vertikal terlihat adanya hirarki ruang dimana ruang yang sakral memiliki perbedaan ketinggian lantai sehingga batas kesakralan terlihat. 


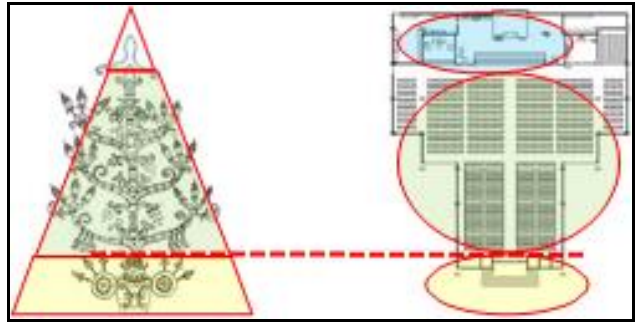

Gambar 5. Perbandingan Struktur Batang Garing dan Struktur Ruang Sumber: Dokumentasi Pribadi

Kanopi fasad terdapat motif Lamantek yang memiliki dua makna yaitu makna positif dan negatif, makna positif adalah pengobatan, kesembuhan dan tenaga, motif ini ingin memberi nilai plus gereja dapat sebagai pengobatan batin. Dahulu yang berasal dari Kepuak, pakaian ini tidak semua orang awam boleh mengganti, alasannya karena patung dilengkapi dengan alat kelamin.

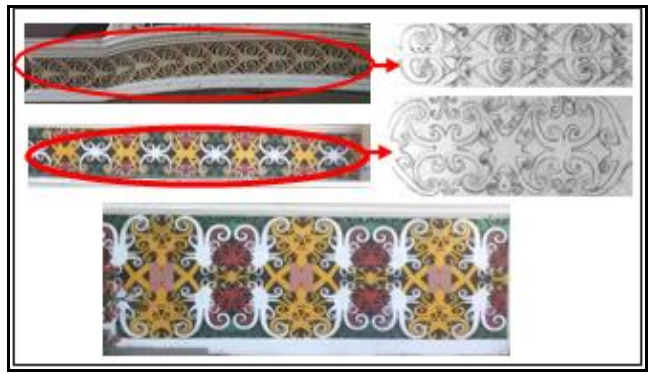

Gambar 6. Ornamen Pada Area Fasad. Sumber: Dokumentasi Pribadi

Pada main entrance akulturasi terjadi hanya pada ukiran bunga terong, karena selebihnya ukiran yang terdapat pada pintu adalah gambar Yesus, malaikat serta simbol dalam katolik dengan motif binatang. Side entrance tidak terjadi akulturasi budaya Dayak, tetapi pada ventilasi terdapat bentukan geometris hasil stilasi dari bangunan rumah betang menjadi bentuk geometris segi 5. Sedangkan pada bagian jendela kaca patri tidak terjadi akulturasi budaya Dayak tetapi terdapat gambar yang menggambarkan ayat pada alkitab, jendela pada dinding bangunan terdapat kaca dengan bentukan tameng Dayak serta bentukan geometri seperti ventilasi.

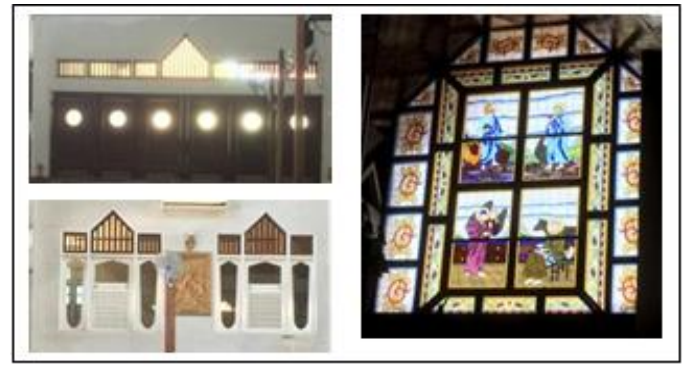

Gambar 7. Jendela Bangunan Gereja.

Pada area panti umat akulturasi terjadi pada patung yang berada di depan dekat main entrance, patung ini menggambarkan spiritualitas orang Dayak, perwujudan harmonisasi antara manusia dengan manusia, manusia dengan alam, sama seperti agama Kaharingan [5] yang percaya tentang Batang Garing yang menunjukan hubungan antara manusia dengan alam. Patung ini merupakan percampuran antara religi Dayak dengan keselamatan Katolik. Pada bagian bawah terdapat patung yang mewujudkan spiritualitas yang takut dan menampilkan kejahatan, kejahatan itu dibebaskan melalui perwataan oleh penginjil yang disimbolkan dengan malaikat yang diukir pada bagian tengah. Malaikat ini mewartakan Yesus Kristus yang tersalib dan bangkit, pada patung Yesus mengenakan pakaian adat Dayak

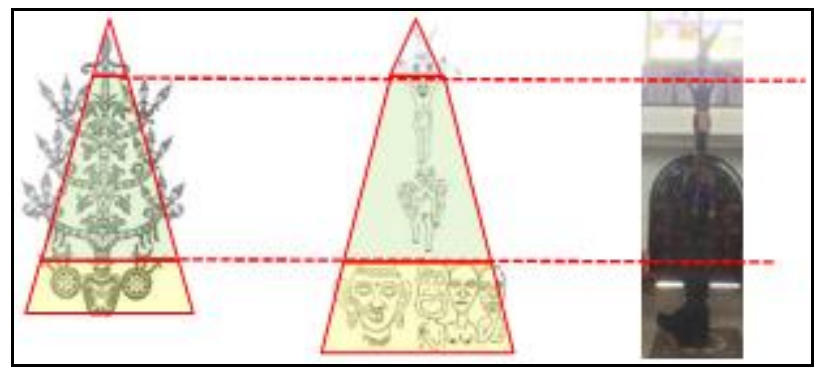

Gambar 8. Perbandingan Batang Garing dengan Patung pada Panti Umat

Pada dinding panti imam terdapat ukiran motif Haramaung, motif ini memiliki makna keberanian dan perlindungan [5] sama seperti Yesus yang melindungi dan berani melawan dosa, serta terdapat ukiran Karekot Bajei yang memiliki makna hubungan antar keluarga. Motif ini digunakan agar hubungan antara Yesus dan umat-Nya dapat lebih erat [5]. Pada panti imam warna yang digunakan adalah merah, kuning dan hitam, terdapat persamaan makna antara panti imam dengan warna yang digunakan. Merah yang berarti abadi sama seperti Yesus yang bangkit dan hidup kekal abadi. Warna kuning berarti keberadaan Tuhan dan keagungan sama dengan makna panti imam dimana Tuhan hadir dengan adanya lampu Tuhan serta area panti imam yang sakral dan agung. Sedangkan hitam berarti penangkis bahaya atau celaka sama seperti penyelamat dengan Yesus yang disalib untuk menyelamatkan umat manusia diperbaharui oleh imam ketika melaksanakan misa di altar atau panti imam [5].

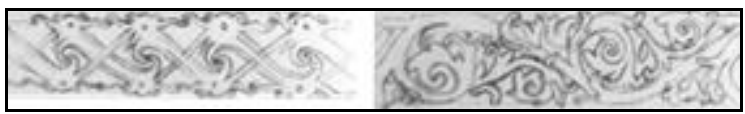

Gambar 9. Ornamen Haramaung dan Karekot Bajei pada panti imam.
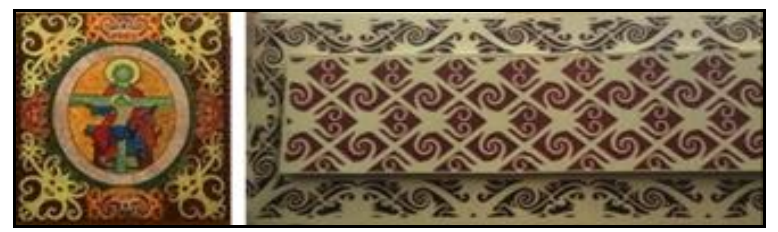

Gambar 10. Plafon dan motif Lamantek pada area panti imam.

Beberapa perabot pada area panti imam terdapat akulturasi budaya Dayak. Pada mimbar terdapat ukiran burung enggang dan burung pelikan, kedua simbol burung ini memiliki persamaan. Burung pelikan merupakan simbol Yesus yang mengorbankan diri-Nya di kayu salib untuk menyelamatkan umat-Nya. 


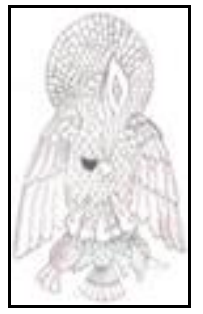

Gambar 11. Ukiran Burung Pelikan.

Sedangkan burung Enggang merupakan perantara media menyampaikan pesan, sama seperti Yesus yang menyampaikan pesan dari Allah Bapa ke umat-Nya. Walaupun kedua burung memiliki perbedaan makna tetapi memiliki persamaan yaitu menggambarkan Yesus.

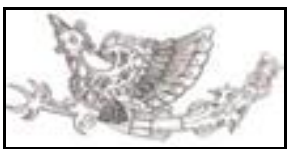

Gambar 12. Ukiran Burung Enggang.

Sedilia yang berada di panti imam memiliki ukiran tentang penguasa alam dan arwah yang menuju surga atau Subayan tujuh, gambaran imam sebagai wakil yang Kuasa dengan bertugas membawa keselamatan bagi umat. (wawancara Romo Matheus Juli).

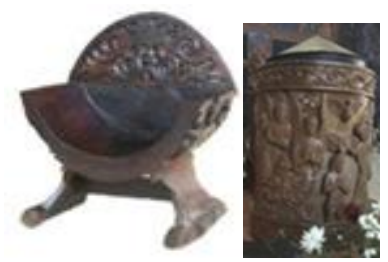

Gambar 13. Sedilia dan Bejana air baptis

Motif pada tempat meletakkan persembahan terdapat akulturasi budaya Dayak pada motif ukiran yang terlihat, yaitu terdapat ukiran bermotif pakis, ukiran ini memiliki makna persatuan dan kekerabatan, kolekte gereja katolik memiliki makna pengumpulan uang sebagai bagian dari persiapan persembahan mempunyai hubungan erat dengan persatuan- persaudaraan dan dengan doa.

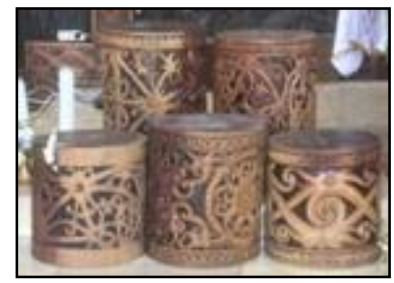

Gambar 14. Tempat meletakkan Kolekte

Tempat meletakkan Tabernakel terdapat ukiran Dayak pada bagian atas dan bawah. Terdapat patung kerahiman Ilahi dengan menggunakan konsep kepercayaan suku dayak yang percaya akan pohon sehingga bentukan patung pada bagian bawah berbentuk pohon dengan penambahan ukiran simbol- simbol Katolik. Pada bagian belakang tabernakel terdapat ukiran Putir Selung
Tamanang. Suku dayak percaya bahwa beras adalah jelmaan Putir Selung Tamanang.

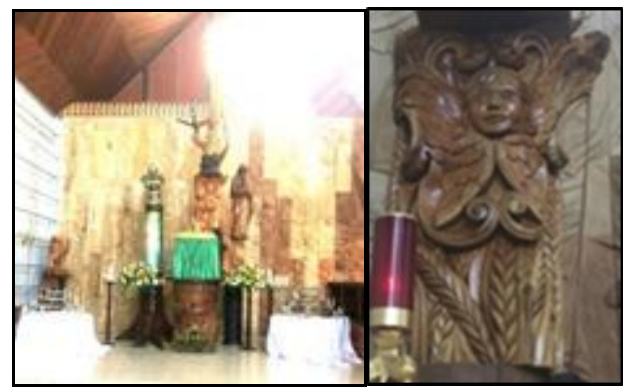

Gambar 15. Area Tabernakel dan Ukiran Putir Selung Tamanang.

Pada bejana air suci terdapat ukiran Dayak pada sisi atas dan bawah bejana ditengah terdapat ukiran kisah Yohanes pembaptis yang membaptis di sungai Yordan, bentukan sungai yang mengalir diaplikasikan dengan ukiran yang melingkar mengelilingi seluruh bejana. Di atas ukiran Putir Selung Tamanang terdapat ukiran pohon dengan bentuk pohon anggur karena anggur merupakan simbol yang hakiki pada Katolik. Pada ukiran pohon terdapat burung Enggang yang bertengger karena suku Dayak percaya akan burung Enggang yang merupakan penguasa alam atas, dan terdapat persamaan antara burung Enggang dan anggur yang melambangkan Yesus.

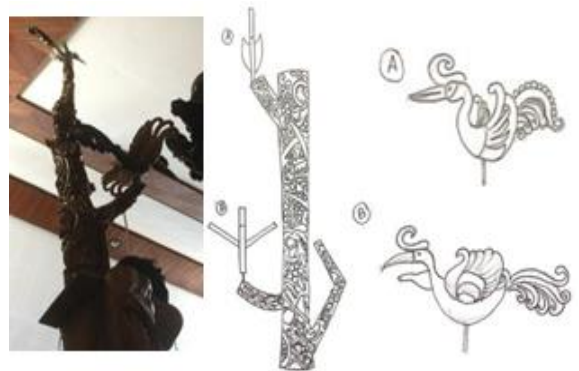

Gambar 16. Patung Pohong Anggur dan Burung Enggang

\section{SIMPULAN}

Dari hasil analisa di atas dapat disimpulkan bahwa wujud akulturasi budaya Dayak pada interior gereja Gemma Galgani di Ketapang serta makna yang terkandung pada ornamen dan elemen interior gereja adalah sebagai berikut:

Akulturasi budaya Dayak terjadi pada struktur organisasi ruang dimana hirarki ruang sama dengan struktur Batang Garing yang polanya terbagi menjadi 3 bagian bawah, tengah dan atas. Area teras atau fasad merupakan bawah, area panti umat merupakan bagian tengah dan area panti imam merupakan atas. Pada elemen pembentuk ruang akulturasi budaya Dayak terlihat pada area panti imam dimana terdapat ukiran dengan warnawarna suku Dayak, mulai dari dinding hingga plafon ornamen dan warna yang digunakan memiliki persamaan makna dengan budaya Katolik. Pada elemen pengisi ruang akulturasi budaya Dayak dapat dilihat pada area panti imam yaitu pada mimbar, sedilia, gong dan bejana air suci serta pada area Tabernakel terdapat unsur Dayak pada perabot yang digunakan, pada perabot tersebut terdapat 
percampuran kepercayaan Katolik yaitu dengan menambahkan simbol-simbol Katolik pada perabot. Elemen dekoratif yang terdapat pada area panti umat yaitu patung yang menggambarkan religiositas masyarakat Dayak yang dicampur dengan patung malaikat dan Yesus yang di Salib sebagai lambang keselamatan.

\section{REFERENSI}

[1] Koentjaraningrat. (2009) Pengantar Ilmu Antropologi. Jakarta: PT Rineka Cipta.

[2] Heuken, S. J., Adolf. (1992)Ensiklopedi Gereja I AG. Jakarta: Yayasan Cipta Loka Caraka,.

[3] Windhu, I. Marsana (1997). Mengenal 30 Lambang dan Simbol Kristiani. Yogyakarta: Penerbit Kanisius.

[4] Abidin, Yunus. (1997) Kumpulan Batik Printing Khas Dayak Kalteng.

[5] Darma, Y. (2003). "Desain Ornamen Tradisional Dayak Ngaju: Tinjauan Elemen Visual, Elemen dan Pola Grafis, Serta Aspek Semiotika nya”. Universitas Kristen Petra. 